06

\title{
Влияние слабого магнитного поля на чувствительность порошкообразного аммината перхлората кобальта различной дисперсности к воздействию сильноточного электронного пучка наносекундной длительности
}

\author{
(C) Г.Г. Савенков, ${ }^{1,2}$ В.А. Морозов, ${ }^{3}$ М.А. Илюшин, ${ }^{1}$ В.М. Кац ${ }^{3}$ \\ ${ }^{1}$ Санкт-Петербургский государственный технологический институт (технический университет), \\ 190013 Санкт-Петербург, Россия \\ ${ }^{2}$ Физико-технический институт РАН им. А.Ф. Иофффе, \\ 194021 Санкт-Петербург, Россия \\ ${ }^{3}$ Санкт-Петербургский университет, \\ 198504 Санкт-Петербург, Россия \\ e-mail: sav-georgij@yandex.ru
}

Поступило в Редакцию 9 декабря 2019 г.

В окончательной редакции 9 декабря 2019 г.

Принято к публикации 28 января 2020 г.

\begin{abstract}
Представлены результаты экспериментов по исследованию влияния слабого магнитного поля на чувствительность порошкообразного аммината перхлората кобальта к воздействию сильноточного электронного пучка (СЭП) наносекундной длительности. В экспериментах применялся порошок аммината перхлората кобальта двух типов дисперсности: среднедисперсный и мелкодисперсный. Установлено, что на чувствительность к воздействию СЭП влияет как слабое магнитное поле, так и дисперсность порошка.
\end{abstract}

Ключевые слова: сильноточный электронный пучок, магнитное поле, амминат перхлората кобальта, взрывчатое превращение.

DOI: $10.21883 / J T F .2020 .08 .49542 .392-19$

\section{Введение}

Исследование возможностей целенаправленного регулирования чувствительности энергонасыщенных материалов (ЭНМ) к внешним воздействиям является одной из фундаментальных проблем физики горения и взрыва [1]. При этом особый интерес вызывает изучение проблемы влияния на взрывную чувствительность ЭНМ к импульсному воздействию сильноточного электронного пучка (СЭП) после их стимулированной обработки в различных физических полях. В первую очередь это связано с поиском возможностей снижения энергетических параметров импульсного электронного пучка. Как следствие, это может привести к снижению массогабаритных характеристик генераторов СЭП, что приведет к инженерному решению проблемы практического использования таких генераторов в различных взрывных устройствах.

В работах [2-5] были проведены исследования влияния на взрывную и тепловую чувствительность энергонасыщенных материалов (смесевого состава на основе нитроглицерина и нитроцеллюлозы, состава на основе пикрата калия, аммината перхлората кобальта и некоторых других) радиационного облучения $\beta$ - и $\gamma$-частицами. Было показано, что предварительное облучение потоками указанных частиц приводит к существенному увеличению их чувствительности к воздействию СЭП наносекундной длительности. Такое повышение чувствитель- ности под действием ионизирующего излучения может быть связано с генерацией в ЭНМ реакционноспособных частиц и изменением их микроструктуры.

В ряде работ [6] и др. предполагается, что одним из механизмов возбуждения в энергонасыщенных материалах быстрых экзотермических реакций (взрывчатых превращений) является дислокационный механизм распада ЭНМ, который собственно и определяет процесс инициирования. По мнению авторов, суть дислокационного механизма состоит в следующем. В ряде случаев при внешних воздействиях (авторы [6], например, говорят о пластической деформации кристалла ЭНМ) происходят образование и движение дислокаций. Дислокации при движении генерируют радикалы. Радикалы запускают процесс распада ЭНМ. Чем выше интенсивность внешнего воздействия (например, степень пластической деформации), тем больше количество (или плотность) дислокаций и их подвижность, а значит, и больше образуется радикалов и тем быстрее протекает распад ЭНМ. Чем быстрее протекает распад, тем выше чувствительность данного ЭНМ к различному виду воздействия.

В настоящее время известно [7], что слабое (магнитная индукция $B<1 \mathrm{~T}$ ) магнитное поле стимулирует подвижность дислокаций и существенно влияет на различные физико-механические и структурно-чувствительные характеристики немагнитных материалов. Поэтому цель настоящей работы состоит в оценке влияния предварительной обработки в слабом магнитном поле (СМП) 
$a$
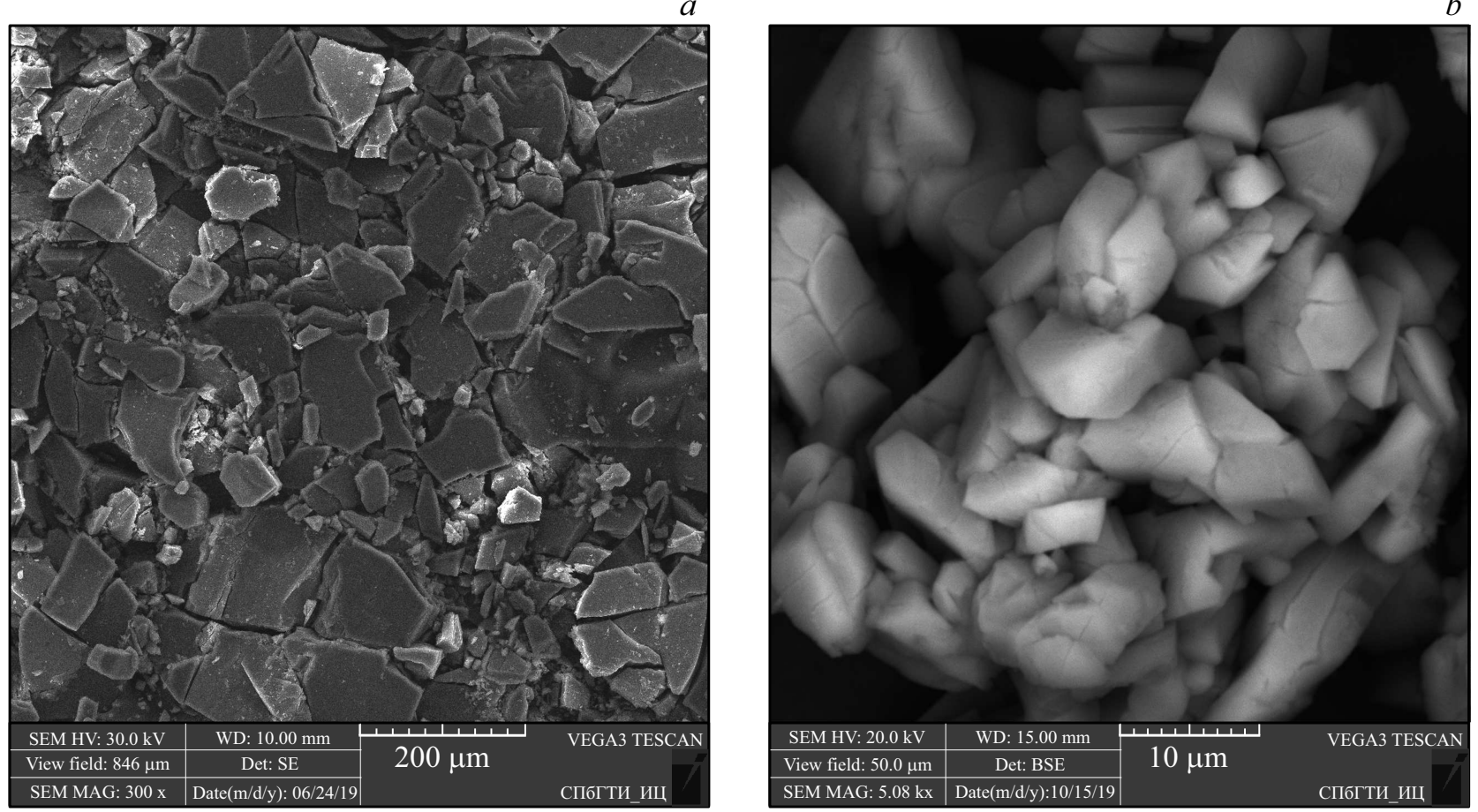

Рис. 1. Исходное состояние аммината перхлората кобальта: $a-$ среднедисперсный NCP; $b-$ мелкодисперсный NCP.

энергонасыщенного материала на его чувствительность к импульсному облучению сильноточным электронным пучком наносекундной длительности.

\section{Энергонасыщенный материал и методика эксперимента}

В качестве исследуемого энергонасыщенного материала был выбран амминат перхлората кобальта (NCP), который был исследован на восприимчивость к СЭП, в том числе после предварительного ионизирующего облучения и в сочетании с наноразмерными добавками различных форм углерода в работах $[4,8,9]$. В экспериментах применялся порошок NCP с двумя типами дисперсности: 1) среднедисперсный - со средним размером частиц $\sim 72 \mu \mathrm{m}$ (рис. $1, a) ; 2$ ) мелкодисперсный со средним размером частиц $\sim 10 \mu \mathrm{m}$ (рис. $1, b)$. Далее они будут обозначаться $\mathrm{NCP}_{\mathrm{I}}$ и $\mathrm{NCP}_{\text {II }}$ соответственно. Отметим, что порошок $\mathrm{NCP}_{\mathrm{II}}$ по дисперсности близок к порошку, который применялся в экспериментах работы $[4,5,8]$ (средний размер его частиц был $\sim 5 \mu \mathrm{m})$.

Порошок NCP (каждого вида дисперсности) запрессовывали в латунные колпачки с внутренним диаметром $4.5 \mathrm{~mm}$ на высоту $2.3 \mathrm{~mm}$. Масса каждой запрессованной в колпачок навески порошка NCP составляла $50 \mathrm{mg}$, плотность $-1.42 \mathrm{~g} / \mathrm{cm}^{3}$. Учитывая массу и габариты запрессованного вещества можно было ожидать, что потенциальные взрывчатые превращения в образцах могут происходить либо в режиме медленного послойного горения, либо в режиме дефлаграции.

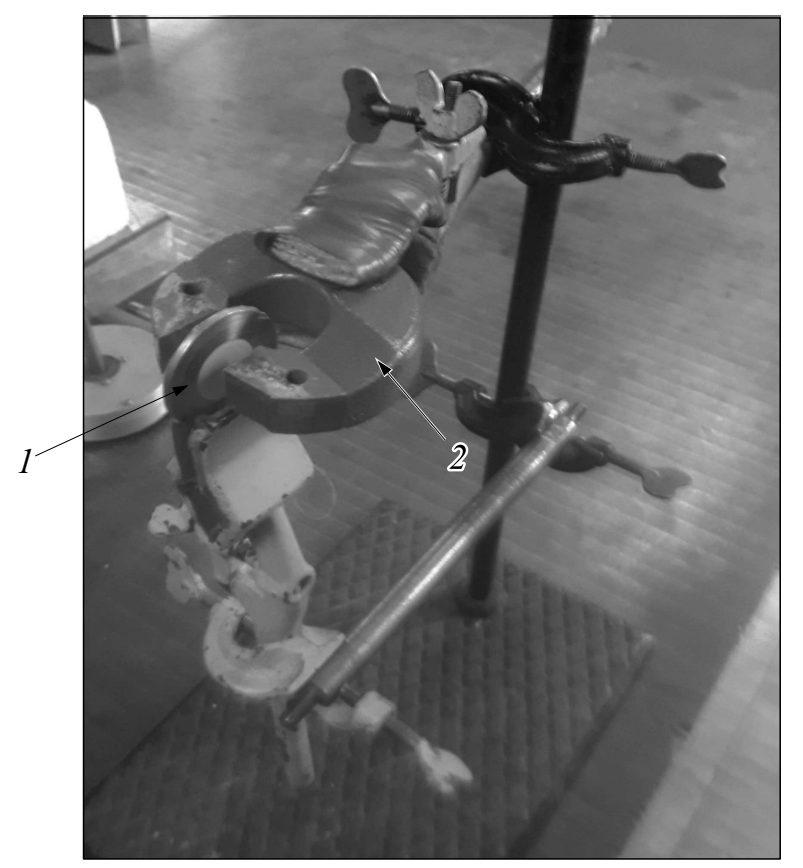

Рис. 2. Схема облучения образца в слабом магнитном поле: 1 - образец, 2 - постоянный магнит.

Схема обработки образца в слабом магнитном поле постоянного магнита с индукцией $45 \mathrm{mT}$ приведена на рис. 2. Измерения индукции проводили с помощью тесламетра ЭМ 4305 (предел допускаемой погрешности 


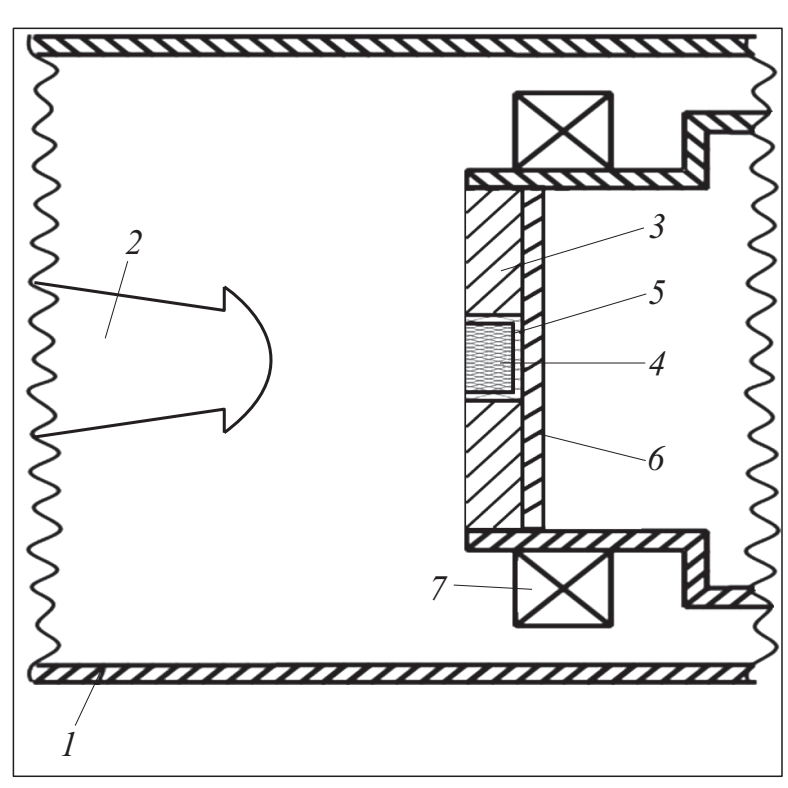

Рис. 3. Экспериментальная схема облучения пучком электронов образца: 1 - вакуумная камера, $2-$ катод, 3 - стальное кольцо, 4 - ЭНМ, 5 - колпачок, 6 - диск.

в диапазоне измерений $0-500 \mathrm{mT}$ составляет $\pm 2.5 \mathrm{mT})$. Облучение в магнитном поле проводилось в течении $45 \mathrm{~min}$. После облучения образец устанавливался в стальное кольцо и помещался в вакуум-камеру электронного ускорителя.

Схема воздействия на образец электронного пучка полностью аналогична схеме, приведенной в работе [8] (рис. 3).

В качестве источника генерации сильноточного электронного пучка использовался электронный ускоритель ГКВИ - 300 [10]. Колпачок с исследуемым ЭНМ устанавливался в стальное кольцо с внешним диаметром - $30 \mathrm{~mm}$. Стальное кольцо 3, в котором находился колпачок 5 с ЭНМ 4, устанавливалось на стальной диск 6 толщиной 2.2-2.5 mm (служил в качестве „дискасвидетеля“), на котором оставался или не оставался отпечаток от колпачка, после того как в образце происходили некие взрывчатые превращения.

Длительность импульса напряжения на его полувысоте составляла 20-40 ns, средняя номинальная энергия электронов в пучке - $250 \mathrm{keV}$, расстояние между катодом и образцом составляло либо $4 \mathrm{~mm}$, либо $5.5 \mathrm{~mm}$, диаметр пучка - $8 \mathrm{~mm}$. Все эксперименты проводились с отсечкой катодного факела [10] и собственного вихревого магнитного поля пучка путем установки на кольцо 3 стальной фольги толщиной $15 \mu \mathrm{m}$. Можно полагать, что установка стальной фольги указанной толщины приводит к уменьшению энергии пучка на $\sim 40 \%$ от номинальной [5]. Время после обработки образца в магнитном поле и до воздействия на него электронного пучка составляло $\sim 1 \mathrm{~h}$.

\section{Результаты экспериментов и их обсуждение}

Результаты экспериментов приведены в таблице. На рис. 4, $a$ представлен вид отпечатка (серия экспериментов 1) от донышка колпачка после взрывчатого превращения NCPI на диске-свидетеле. На рис. $4, b$ представлена тыльная сторона диска с выдавленным конусом металла (отпечаток и конус указаны стрелками).

Прежде всего, анализ результатов, приведенных в таблице и в совокупности с результатами работ $[4,5,8]$, показал, что, чем ниже дисперсность порошка ЭНМ, тем выше восприимчивость NCP к воздействию сильноточного электронного пучка.

Из результатов, представленных в таблице, видно, что предварительная обработка вещества в СМП оказала существенное влияние как на чувствительность к воздействию СЭП, так и на энергетические свойства аммината перхлората кобальта. Для $\mathrm{NCP}_{\mathrm{I}}$ глубина отпечатка на $30-40 \%$ превосходит глубину отпечатка колпачка с необработанным в магнитном поле веществе при воздействии на него СЭП с большей энергией и, практически, в 2 раза превосходит глубину отпечатка при действии СЭП с той же энергией.

Для $\mathrm{NCP}_{\mathrm{II}}$ обработка в магнитном поле не только восстановила чувствительность к воздействию СЭП со слабой энергетикой, но и восстановила энергетический режим взрывчатого превращения (по всей видимости режим дефлаграции).

С чем же может быть связано резкое увеличение чувствительности и глубины отпечатка на диске-свидетеле? Прежде всего, необходимо отметить, что исследуемое вещество, исходя из его поэлементного состава, должно с большой долей вероятности относиться к классу парамагнетиков.

Результаты экспериментов по инициированию аммината перхлората кобальта, предварительно обработанного в слабом магнитном поле

\begin{tabular}{|c|c|c|c|c|}
\hline № & $\begin{array}{c}\text { Тип порошка } \\
\text { NCP }\end{array}$ & $\begin{array}{c}\text { Доля энергии, } \\
\text { \% }\end{array}$ & $\begin{array}{c}\text { Наличие } \\
\text { обработки в } \\
\text { магнитном поле }\end{array}$ & $\begin{array}{c}\text { Глубина } \\
\text { отпечатка, } \\
\text { mm }\end{array}$ \\
\hline 1 & \multirow{3}{*}{$\mathrm{NCP}_{\mathrm{I}}$} & 60 & - & $0.35-0.45$ \\
\hline 2 & & 50 & - & $0.25-0.35$ \\
\hline 3 & & 50 & + & $0.5-0.6$ \\
\hline 4 & \multirow{3}{*}{$\mathrm{NCP}_{\mathrm{II}}$} & 60 & - & $0.2-0.25$ \\
\hline 5 & & 50 & - & - \\
\hline 6 & & 50 & + & $0.2-0.25$ \\
\hline
\end{tabular}

Примечание. 1. На каждый вид испытания приходилась серия из 3-х экспериментов; 2. В 5-ом виде испытаний возбудить взрывчатые превращения не удалось. 
$a$

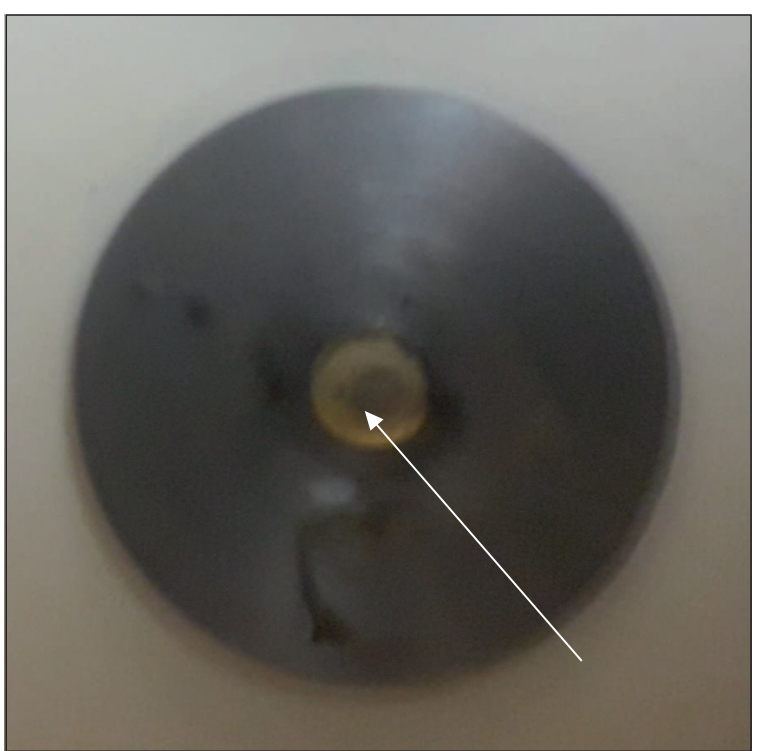

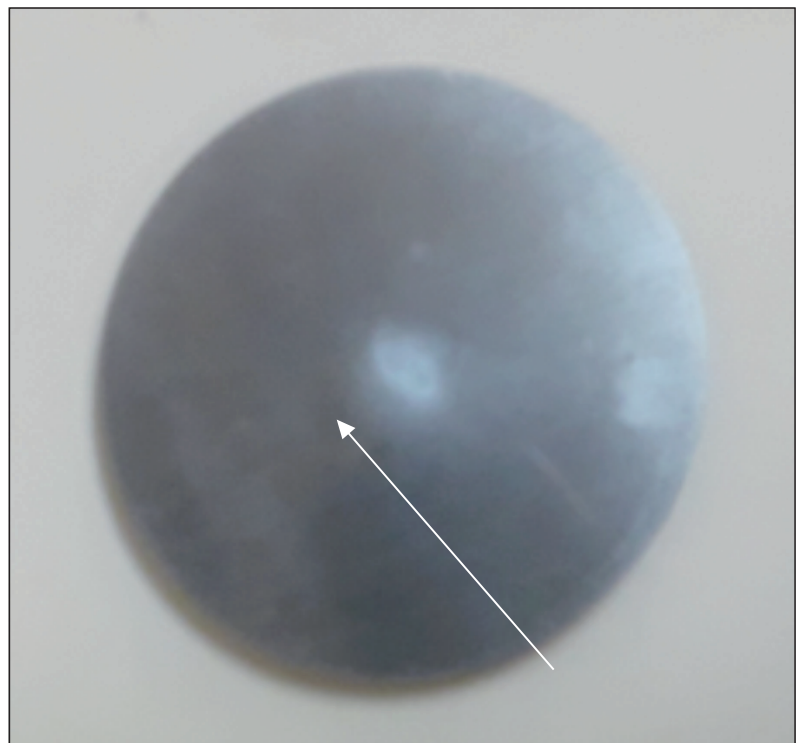

Рис. 4. Отпечаток на фронтальной поверхности диска-свидетеля (a) и выдавленный конус металла на тыльной поверхности диска (указан стрелкой) $(b)$.

Это связано с тем, что кобальт является чистым ферромагнетиком и обладает большим магнитным дипольным моментом атома, подавляющим диамагнитные свойства вещества [11]. И, наконец, хорошо известно, что соли элементов семейства железа (к которому относится кобальт) обладают хорошо развитыми парамагнитными свойствами [12]. Кроме того, в процессе распада (который может начаться под действием СМП) исследуемого комплекса происходит частичное восстановление $\mathrm{Co}^{+3}$ и образуется $\mathrm{Co}_{3} \mathrm{O}_{4}$ [13], который может рассматриваться как смешанный окисел $\mathrm{CoO} \cdot \mathrm{Co}_{2} \mathrm{O}_{3}$ или как соль кобальта(III) кобальта(II) $\mathrm{Co}\left[\mathrm{Co}_{2} \mathrm{O}_{4}\right]$.

Таким образом, априори, в исследуемом нами веществе присутствует достаточно большое количество парамагнитных объектов (локализованных электронов, дырок, триплетных экситонов, ион-радикалов), способных вступать в обменное взаимодействие [7]. Под действием слабого магнитного поля, которому подвергается исследуемое вещество, в нем происходит образование радикальных пар (РП).

Как известно [10], СЭП обладает и механическим полем, которое воздействует на вещество суммарным давлением, состоящим из давления, развиваемого за счет механического импульса электронов, и давления, создаваемого ударной волной, возникающей при действии на образец электронного пучка. В нашем случае суммарная величина давления не превосходит 200-300 МРа, что сопоставимо с давлением прессования взрывчатых составов в оболочки средств инициирования [14]. Тем не менее такое давление приводит к пластической деформации (ПД) (ее величина может достигать с учетом низкой плотности запрессованного в колпачок NCP достаточно высоких значений) вещества в колпачке. В свою оче- редь, ПД вызывает рост концентрации парамагнитных центров, что приводит к увеличению вероятности интеркомбинационных переходов (ИКП) между синглетными $(S)$ и триплетными $(T)$ состояниями радикальных пар. Полагают [15], что при воздействии СМП увеличивается заселенность $T$-состояний РП, обладающих значительно меньшими энергиями разрыва. Термическое действие электронного пучка стимулирует обменные реакции между РП в $S$ - и $T$-состояниях, которые запускают реакции разложения и в конечном итоге это приводит к запуску реакций взрывчатых превращений. Чем больше концентрация РП, тем выше вероятность ИКП и возникновения реакций ВП и соответственно выше чувствительность ЭНМ к внешнему воздействию (в нашем случае к воздействию СЭП).

Увеличение глубины отпечатка можно объяснить снижением длины участка перехода горение-взрывное горение и более высокой скоростью нарастания давления на участке взрывного горения.

\section{Заключение и выводы}

Авторы не претендуют на полное объяснение обнаруженных в рамках настоящей работы эффектов как в силу их сложности, так и вследствие недостатка научных теорий влияния СМП на немагнитные материалы в целом. Возможно, здесь потребуется привлечение теории материалов с эффектом памяти, но не формы, а магнитного поля. Не ясно также как долго сохраняются свойства вещества после его обработки в слабом магнитном поле. Тем не менее на основании проведенных исследований можно сделать следующие выводы: 
1. Чувствительность порошкообразного аммината перхлората кобальта к воздействию СЭП связана с его дисперсностью: чем ниже дисперсность порошка, тем выше восприимчивость NCP к воздействию сильноточного электронного пучка.

2. Предварительная обработка энергонасыщенного материала (аммината перхлората кобальта) в СМП приводит к увеличению его чувствительности к воздействию СЭП наносекундной длительности.

3. Одновременно с увеличением чувствительности NCP происходит увеличение давления в волне дефлаграционного давления, что может быть связано с сокращением участка перехода от послойного горения к дефлаграционному горению.

\section{Конфликт интересов}

Авторы заявляют, что у них нет конфликта интересов.

\section{Список литературы}

[1] Физика взрыва. Т. 1. / Под ред. Л.П. Орленко. М.: Физматлит, 2002. $832 \mathrm{c}$.

[2] Коптелов А.А., Милёхин Ю.М. // Физика горения и взрыва. 2007. Т. 43. № 6. С. 69-74.

[3] Савенков Г.Г., Морозов В.А., Мазур А.С., Лукин А.А. // Химическая физика. 2015. Т. 34. № 9. С. 33-36.

[4] Савенков Г.Г., Морозов В.А., Персинен А.А., Оськин И.А., Брагин В.А., Лукин А.А. // Письма в ЖТФ. 2016. Т. 42. Вып. 17. С. 28-33.

[5] Савенков Г.Г., Морозов В.А., Илюшин М.А., Кац М.А. // ЖТФ. 2018. Т. 88. Вып. 7. С. 1050-1056.

[6] Клименко В.Ю. // International Conference „Shock Waves in Condensed Matter“, Saint-Petersburg-Novgorod, 2010. Сборник трудов конференции. 2010. С. 145-150.

[7] Головин Ю.И. // ФТТ. 2004. Т. 46. Вып. 5. С. 769-803.

[8] Савенков Г.Г., Морозов В.А., Илюшин М.А., Оськин И.А., Брагин В.А., Козлов А.С. // ЖТФ. 2017. Т. 87. Вып. 11. C. $1701-1706$

[9] Савенков Г.Г., Морозов В.А., Илюшин М.А., Кач, В.М. // ЖТФ. 2018. Т. 88. Вып. 7. С. 1050-1056.

[10] Морозов В.А., Савенков Г.Г., Брагин В.А., Лукин А.А., Кач В.М. // ЖТФ. 2012. Т. 82. Вып. 5. С. 129-134.

[11] Мирдель Г. Электрофизика. М.: Мир, 1972. 608 с.

[12] Зейти Ф. Современная теория твердого тела. М.-Л.: ГИТТЛ, 1949. $736 \mathrm{c}$.

[13] Тверьянович Ю.С., Тверьянович А.С., Илютин М.А., Аверьянов А.О., Смирнов А.В., Шугалей И.В. // ЖОХ. 2017. Т. 87. Вып. 11. С. 1860-1864. [Tverjanovich Yu.S., Tverjanovich A.S., Ilyushin M.A., Averyanov A.O., Smirnov A.V., Shugalei I.V. // Rus. J. Gen. Chem. 2017. Vol. 87. N 11. P. 2600-2604.]

[14] Карпов П.П. Средства инициирования. М.: Оборонгиз, 1945. 272 c.

[15] Молочкий М.И. // ФТТ. 1991. Т. 33. Вып. 10. С. 3112-3114. 